\title{
Phytoprotection
}

\section{Simulation of crop-weed competition : Models and their applications}

\section{S.E. Weaver}

Volume 77, numéro 1, 1996

URI : https://id.erudit.org/iderudit/706096ar

DOI : https://doi.org/10.7202/706096ar

Aller au sommaire du numéro

\section{Éditeur(s)}

Société de protection des plantes du Québec (SPPQ)l

\section{ISSN}

0031-9511 (imprimé)

1710-1603 (numérique)

Découvrir la revue

\section{Citer cet article}

Weaver, S. (1996). Simulation of crop-weed competition : Models and their applications. Phytoprotection, 77(1), 3-11. https://doi.org/10.7202/706096ar

\section{Résumé de l'article}

La compétition entre les cultures et les mauvaises herbes est un phénomène complexe. Des modèles de simulation exhaustifs, orientés vers les processus et traitant la compétition selon une approche systématique plutôt qu'empirique, peuvent offrir un aperçu des relations qui existent entre la compétition, la densité des cultures et des mauvaises herbes, les périodes relatives d'émergence, les divers caractères morphologiques et physiologiques, ainsi que les niveaux de ressources. Ils peuvent aussi être utilisés pour la prévision en tant que composante d'une approche systémique de lutte contre les mauvaises herbes. Cet article passe en revue les caractéristiques de quelques modèles de simulation récents de compétition entre les cultures et les mauvaises herbes, les espèces pour lesquelles leurs paramètres ont été adaptés, ainsi que leurs applications. Jusqu'à maintenant, ces modèles ont été principalement utilisés afin de prédire les pertes de rendement attribuables à la compétition exercée par les mauvaises herbes. Leur aptitude à simuler la production de graines de mauvaises herbes en réponse à certains facteurs environnementaux n'a pas été exploitée. La prochaine étape consistera à relier les modèles de simulation de compétition cultures-adventices aux modèles de dynamique des populations de mauvaises herbes, pour améliorer notre aptitude à prédire dans le temps les effets de diverses stratégies de lutte contre les mauvaises herbes. Les avantages et inconvénients de l'approche par modèles pour résou dre les problèmes de lutte contre les mauvaises herbes sont discutés.
Ce document est protégé par la loi sur le droit d'auteur. L'utilisation des services d'Érudit (y compris la reproduction) est assujettie à sa politique d'utilisation que vous pouvez consulter en ligne.

https://apropos.erudit.org/fr/usagers/politique-dutilisation/ 


\title{
Simulation of crop-weed competition : Models and their applications
}

\author{
Susan E. Weaver ${ }^{1}$
}

Received 1995-07-14; accepted 1996-01-25

Competition between crops and weeds is a complex phenomenon. Comprehensive, process-oriented simulation models which treat competition in a mechanistic rather than an empirical fashion, can offer insight into relationships among competition, crop and weed density, relative time of emergence, various morphological and physiological traits, and resource levels. They can also be used for prediction as part of a systems approach to weed management. This paper reviews the features of a number of recent simulation models of crop-weed competition, the species for which they have been parameterized, and their applications. To date, these models have been used primarily to predict crop yield losses due to weed competition. Their ability to simulate weed seed production in response to the environment has not been exploited. The next step is to link simulation models of crop-weed competition to weed population dynamics models, in order to improve our ability to predict the effect of various weed management strategies over time. Advantages and drawbacks of a modeling approach to weed management problems are discussed.

Weaver, S.E. 1996. Simulation de la compétition culture-mauvaises herbes : les modèles et leurs applications. PHYTOPROTECTION 77 : 3-11.

La compétition entre les cultures et les mauvaises herbes est un phénomène complexe. Des modèles de simulation exhaustifs, orientés vers les processus et traitant la compétition selon une approche systématique plutôt qu'empirique, peuvent offrir un aperçu des relations qui existent entre la compétition, la densité des cultures et des mauvaises herbes, les périodes relatives d'émergence, les divers caractères morphologiques et physiologiques, ainsi que les niveaux de ressources. Ils peuvent aussi être utilisés pour la prévision en tant que composante d'une approche systémique de lutte contre les mauvaises herbes. Cet article passe en revue les caractéristiques de quelques modèles de simulation récents de compétition entre les cultures et les mauvaises herbes, les espèces pour lesquelles leurs paramètres ont été adaptés, ainsi que leurs applications. Jusqu'à maintenant, ces modèles ont été principalement utilisés afin de prédire les pertes de rendement attribuables à la compétition exercée par les mauvaises herbes. Leur aptitude à simuler la production de

1. Harrow Research Centre, Agriculture and Agri-Food Canada, Harrow, Ontario, Canada NOR $1 \mathrm{GO}$ 
graines de mauvaises herbes en réponse à certains facteurs environnementaux n'a pas été exploitée. La prochaine étape consistera à relier les modèles de simulation de compétition cultures-adventices aux modèles de dynamique des populations de mauvaises herbes, pour améliorer notre aptitude à prédire dans le temps les effets de diverses stratégies de lutte contre les mauvaises herbes. Les avantages et inconvénients de l'approche par modèles pour résoudre les problèmes de lutte contre les mauvaises herbes sont discutés.

\section{INTRODUCTION}

A number of simulation models of cropweed competition have appeared in the literature in recent years. Most of these have evolved from models of crops grown in monoculture, and include coupled growth models for each of the competing species, as well as a simulation of the distribution of limiting resources among the species. Forms of interference between weeds and crops other than competition for resources, such as allelopathic interactions, are not addressed in these models. They are dynamic and process-oriented in approach, and simulate weed and crop growth in response to the environment based on underlying physiological and physical processes. Simulation models vary in size and complexity in relation to the intended application, and combine both mechanistic and empirical, or descriptive, elements. Processes which are well understood, such as light interception and photosynthesis, are treated mechanistically, whereas those which are poorly understood, such as resource allocation, are treated descriptively. The distinction between models intended for research and models intended for application, i.e. prediction, is not well defined. Many of the existing models of crop-weed competition have been designed and used for both purposes. The question arises : To what extent can such models contribute to the development of practical weed management programs?

The vast majority of studies on weedcrop competition are empirical in nature. Most have focused on the relationship between weed density or relative time of weed emergence and crop yield at harvest. Simple regression models based on these studies have been developed to predict crop yield losses. The estimated parameter values in the regression equations often vary considerably with location and weather conditions (Bauer et al. 1991; Kropff et al. 1992a). Empirical descriptions of the outcome of weed-crop competition are valid only for the conditions under which they were measured. Many time-consuming and costly field experiments must be repeated over many sites and years in order to arrive at general conclusions. Simulation models provide a means of conducting competition experiments under a wide variety of weather conditions, and generating both predictions of crop yield losses and hypotheses for testing. Simulation rnodels must run on historical weather data and so cannot be truly predictive. They can, however, be used for prediction over a set of average and extreme environmental conditions to provide users with alternative solutions of a problem.

Simulation models also provide insight into the process of competition. A simulation approach forces one to focus on why something happens, rather than simply documenting what happens under one set of conditions after another. Factors which are most important in influencing the outcome of competition or which require precise measurement can be readily identified through sensitivity analyses. Relationships between the environment and the various morphological and physiological characteristics of species, which determine their relative competitive ability, are complex. Models provide a means of testing hypotheses about relationships among complex variables, integrating existing knowledge, and exposing the gaps in our understanding that require further research. Models also may have an instructive value for disseminating knowledge. 
On the other hand, simulation models have a number of characteristics which limit their usefulness for practical weed management. A great deal of time is required to develop a comprehensive model of crop-weed competition, and to quantify the morphological and physiological characteristics of the competing species, either through literature searches or actual experiments. Model validation, sensitivity analyses, and documentation are equally time consuming, and unfortunately are not always completed. Independent data sets, i.e. data not used in parameterization of the model, which should be used for model validation may be unavailable. Some modelers prefer to conduct model evaluation rather than validation. In this process, species' parameter values are derived from a wide range of environmental conditions, various components of the model are checked for internal consistency, and the output or predictive value of the model is compared against observed data. In practice, the extent of model evaluation and analysis has varied greatly. Documentation and program listings for many models are too brief, confusing or inaccessible. Some models have a "simulation environment" superstructure, governing file handling and output format, which are designed to enhance their utility but also greatly increase their complexity. The more complex a model is, the more difficult it is for users who were not involved in development of the model to modify it for their particular application. As a result, would-be users often end up creating new models rather than customizing existing ones. Lastly, useful models must be updated frequently to incorporate new information and advances in understanding.

\section{EXAMPLES OF SIMULATION MODELS OF CROP-WEED COMPETITION}

One of the most comprehensive and welldocumented models of crop-weed competition is INTERCOM (Kropff and Spitters 1992; Kropff and van Laar 1993). It derives from early work on competition by Spitters and Aerts (1983) and Spitters (1989), and from simulation models of crop growth in monoculture (de Wit et al. 1978; Spitters et al. 1989). Growth of each species is expressed at the population rather than individual plant level, i.e. in $\mathrm{kg}^{\mathrm{d}}$ dry matter ha ${ }^{-1}$, and the model runs from either sowing or emergence until crop or weed maturity with a time step of $1 \mathrm{~d}$. The approach used in this model to describe light interception and distribution among the competing species, based on Spitters and Aerts (1983), has been followed in many other models (Graf et al. 1990b; Kiniry et al. 1992; Wiles and Wilkerson 1991). The light profile within the canopy is calculated as a function of leaf area index, plant height, the vertical distribution of leaf area, and the light extinction coefficient of each species. A homogeneous, horizontal distribution of leaf area is assumed for each species. Competition for water is simulated by calculating the soil water balance, and reducing photosynthesis and growth by the ratio between actual and potential (i.e. when water is not limiting) transpiration for each species. The model does not currently simulate competition for nutrients, but Spitters (1989) and Kropff (1993) have outlined a simple approach that could be followed to simulate competition for nitrogen. The model has been parameterized and evaluated for a wide range of crop and weed species, locations and weather conditions (Table 1). In most cases, the model accurately predicts weed and crop growth in both mixtures and monocultures. Kropff et al. (1993) noted, however, that yield losses of corn (Zea mays L.) in competition with barnyard grass [Echinochloa crus-galli (L.) Beauv.] were severely underestimated in an extremely dry year, because the model did not account for the effects of drought on morphological development, particularly a reduction in corn stem elongation.

Wilkerson et al. (1990) developed the model SOYWEED to simulate competition between soybeans [Glycine $\max (\mathrm{L}$.) Merr.] and cocklebur (Xanthium strumarium L.). The model is an extension of the crop growth model SOYGRO (Jones et al. 1987) and simulates competition for both light and water. In this model, competition for light is a function of weed area of influence, defined as "a rectangle 
Table 1. Principal applications of published models of crop-weed competition

\begin{tabular}{|c|c|c|c|}
\hline Crop & Weed & $\begin{array}{l}\text { Resources for which } \\
\text { plants compete }\end{array}$ & Reference \\
\hline $\begin{array}{l}\text { ALMANAC } \\
\text { corn, soybeans, } \\
\text { spring wheat }\end{array}$ & $\begin{array}{l}\text { johnsongrass, } \\
\text { cocklebur and } \\
\text { foxtail spp. }\end{array}$ & light, water, nitrogen & Kiniry et al. 1992 \\
\hline $\begin{array}{l}\text { INTERCOM } \\
\text { sugarbeet }\end{array}$ & lamb's-quarters & light, water & $\begin{array}{l}\text { Kropff and Spitters } 1992 \\
\text { Kropff et al. 1992b }\end{array}$ \\
\hline corn & barnyard grass & light, water & Kropff et al. 1993 \\
\hline tomato & mixed species & light, water & $\begin{array}{l}\text { Kropff et al. 1992a } \\
\text { Weaver et al. } 1992 .\end{array}$ \\
\hline rice & barnyard grass & light, water & Kropff et al. 1993 \\
\hline winter wheat & wild oats & light & Weaver et al. 1994. \\
\hline winter wheat & mixed species & light & Lotz et al. 1990 \\
\hline $\begin{array}{l}\text { NTRM-MSC } \\
\text { corn }\end{array}$ & redroot pigweed & light, water, nitrogen & Ball and Shaffer 1993 \\
\hline $\begin{array}{l}\text { SOYWEED } \\
\text { soybeans }\end{array}$ & cocklebur & light, water & Wilkerson et al. 1990 \\
\hline $\begin{array}{l}\text { UNNAMED } \\
\text { rice }\end{array}$ & mixed species & light, nitrogen & Graf et al. 1990b \\
\hline rice & barnyard grass & light, nitrogen & Graf and Hill 1992 \\
\hline wheat & wild oats & light & $\begin{array}{l}\text { Ryel et al. } 1990 \\
\text { Barnes et al. } 1990 \\
\text { Beyschlag et al. } 1990\end{array}$ \\
\hline barley & wild oats & light & Dunan et al. 1994 \\
\hline
\end{tabular}

of width equal to the rowspacing and length down the crop row equal to the weed canopy diameter", and a competitive factor which represents the relative ability of the weed and crop to intercept light. The first version of SOYWEED allowed for heterogeneity in the horizontal distribution of leaf area, but did not explicitly account for differences in weed and crop heights. Subsequently, Wiles and Wilkerson (1991) incorporated an improved submodel (LTCOMP) of light competition into SOYWEED, with light interception simulated as a function of plant height, the amount and vertical distribution of leaf area, and the extinction coefficient of each species. The addition of LTCOMP improved the ability of SOYWEED to simulate both soybean and cocklebur growth in mixture. SOYWEED focuses on growth in weed leaf area and biomass as it affects crop yield, but does not simulate weed seed production. To date, it has been validated with data from only one site and year (Table 1).
Graf et al. (1990a) constructed a growth model for irrigated rice (Oryza sativa L.) in monoculture, and then expanded it to include competition with multiple weed species for light and nitrogen (Graf et al. 1990b). Their model was parameterized and tested with field experiments involving natural populations of mixed weed species. Rather than treating all the weed species individually, they divided the weed flora into six groups based on differences in leaf shape, growth form, height and phenology. Competition for light is modeled using an approach similar to that of Spitters and Aerts (1983), while competition for nitrogen is based on the proportion of the root space explored by the crop and each of the weed groups. Graf and Hill (1992) parameterized and validated the model for competition between barnyardgrass and irrigated rice. The model accurately predicted the effect of various rice and barnyard grass densities on rice yield. 
Several other crop-weed competition models have been derived from models initially designed to examine the impact of soil erosion and tillage practices on crop productivity (Table 1). Kiniry et al. (1992) developed the model ALMANAC (Agricultural Land Management Alternatives with Numerical Assessment Criteria) to simulate competition between two plant species for light, nutrients (nitrogen and phosphorous), and water. It is intended for practical applications including intercropping and weed management, and includes many of the subroutines and functions for water balance, nutrient cycling, and plant growth from the growth model EPIC (Erosion Productivity Impact Calculator, Williams et al. 1989). ALMANAC has been parameterized and evaluated for two-way combinations of johnsongrass [Sorghum halepense (L.) Pers.], foxtail species [Setaria faberii Herrm. and $S$. viridis (L.) Beauv.] or cocklebur in corn, soybeans or spring wheat (Triticum aestivum L.). Many of the species parameters were estimated from the literature. Simulated crop yields at different weed densities and times of emergence were then compared to data from published field studies over various locations and years. Ball and Shaffer (1993) developed NTRM-MSC (Nitrogen, Tillage Residue, Management - Multiple Species Competition) from the model NTRM (Shaffer and Larson 1987), which was originally designed for crop monocultures and applied to various soil management problems. NTRM-MSC models competition between 2 to 10 plant species. It simulates light interception by the competing species in a manner similar to the models described above, but also simulates in detail soil water and nitrogen dynamics and root competition for these resources. Ball and Shaffer (1993) parameterized the model for corn and redroot pigweed (Amaranthus retroflexus L.), using data from monocultures of each species grown in the field. Model output was then compared against data from mixtures of the two species at one site in $1 \mathrm{yr}$, with and without irrigation and nitrogen fertilization. The model predicted biomass and leaf area accumulation of each species in mixture with reasonable accuracy. However, the authors noted that the model did not account for observed differences in pigweed canopy architecture between monocultures and mixtures, and therefore underestimated pigweed light interception in monoculture.

Ryel et al. (1990) developed a detailed simulation model of competition for light within a multispecies canopy. The model is not dynamic in the sense of simulating growth of the competing species over time. Rather, it simulates instantaneous light interception and net photosynthesis of each species in a mixed canopy as a function of canopy structure, photosynthetic characteristics and incident radiation. It has been calibrated and tested for monocultures and mixtures of irrigated spring wheat and wild oats (Avena fatua L.) (Barnes et al. 1990; Beyschlag et al. 1990).

Dunan et al. (1994) constructed a simulation model of weed-crop competition for light which includes an economic submodel in order to analyse the profitability of different weed management strategies. The approach used to simulate competition for light is similar to that of Spitters and Aerts (1983), although plant height was not taken into account. Water and nutrients are assumed to be nonlimiting. They parameterized the model for wild oats in irrigated barley (Hordeum vulgare L.), using growth analysis experiments for calibration, and a field replacement series experiment as well as a commercial field survey for model validation.

\section{MANAGEMENT APPLICATIONS}

Most of the above simulation models were intended to be used not only for research, but to provide insight into how to improve methods of weed management. To date, however, there have been relatively few published applications of existing models independent of model development and validation. Of these, the majority address potential rather than actual applications, by simulating the effect of changes in various parameters, largely without field confirmation.

Several simulation studies have dealt with the effects of weed density and time 
of emergence on crop yield losses, and on the way in which environmental variation influences these relationships. Kropff et al. (1992a) used INTERCOM to analyse the effect of weed height on the parameter estimates of simple regression models predicting crop yield losses. They simulated sugarbeet (Beta vulgaris L.) yield losses over a wide range of lamb'squarters (Chenopodium album L.) densities and times of emergence, with three different maximum weed heights. These simulated data were then fitted to the regression models of Cousens et al. (1987) and Kropff and Spitters (1991), which predict yield losses based on weed density and time of emergence, or relative weed leaf area, respectively. The latter model, which integrates in one variable the combined effects of weed density and time of emergence, was derived from the model INTERCOM by Kropff and Spitters (1991). Weaver et al. (1992) demonstrated how INTERCOM could be used to analyse the influence of weed density, weed height and water availability on the timing of the critical period of competition in transplanted and direct-seeded tomatoes (Lycopersicon esculentum L.). Kropff et al. (1993) and Dunan et al. (1994) used a modeling approach to analyse the extent to which increasing crop density could decrease weed competitive effects. Dunan et al. (1994) used a simulation model to calculate economic thresholds of wild oats in barley and showed that these agreed with economic threshold values determined empirically.

Simulation models may also be used to analyse morphological and physiological traits which contribute to competitive ability. Lotz et al. (1991) found pronounced differences in competitive ability among sugarbeet cultivars which differed in leaf angle distribution and therefore in light interception. Weaver et al. (1994) showed that small differences in the timing of stem extension in winter wheat could have a large effect on the outcome of competition with wild oats, using model simulations. These and other studies (Barnes et al. 1990; Beyschlag et al. 1990), have demonstrated that morphological traits which affect canopy structure are more important than photosynthetic traits in determining competitive ability for light. These studies may be useful to breeders seeking to develop more competitive crop cultivars, although the trade-off between competitiveness and yield potential must be considered.

Finally, simulation models can form the basis of a systems approach to weed management, in which the contribution of a number of management options can be evaluated. Dunan et al. (1994) used a simulation model to assess the importance of genetic (i.e., choice of crop cultivar), cultural and chemical weed control strategies for wild oats in barley. Lotz et al. (1990) analysed the effect of omission of herbicides in winter wheat in relation to autumn or spring emerging weeds and maximum weed height, using INTERCOM. Ball and Shaffer (1993) used a modeling approach to examine competition between redroot pigweed and corn under low and high input conditions with respect to fertility and irrigation. Wiles et al. (1991) developed an instructional computer game, WEEDING, which includes elements of SOYWEED and HERB, a decision model for postemergence weed control in soybeans and corn (Wilkerson et al. 1991). WEEDING simulates crop and weed growth from planting until harvest, allows the user to make weed control and other management decisions during the simulation, and demonstrates the economic consequences of these decisions.

\section{RECOMMENDATIONS}

Simulation models of crop-weed competition have the potential to contribute to improved weed management strategies. Their potential has not been fully realized, in part because more time has been spent developing models than applying them. There are a number of ways in which the contribution of simulation models to practical weed management programs could be increased:

1. Modeling and experimentation should proceed in parallel, preferably in interdisciplinary groups. There should be continual feedback between the two, not just to validate the model or to make predictions, but also to test hypotheses about the mechanisms and assumptions included in the model. 
2. Models need to be written in widely available programming languages, with an accessible structure and thorough documentation so that they can be shared. Models should have a modular form, so that subroutines or subprograms can be transported from one model to another.

3. Models simulating crop-weed competition should be linked to weed population dynamics models. The ability of crop-weed competition models to simulate weed growth in a crop under varying environmental conditions makes them well suited to simulate weed seed production in relation to different weed management strategies over time.

4. Users of simulation models must be cognizant of the range of morphological and physiological variation within a weed species across its geographic range, and not uncritically adopt values for species' parameters that were derived elsewhere. Morphological plasticity within weed populations is also a challenge for modelers of weed growth and development.

5. Simulation models of crop-weed competition, together with long-term weather records, could be used to estimate the risk associated with empirical predictions of crop yield losses and weed seed production. Risk estimates would be useful in cost-benefit analyses of weed management strategies.

Of the above recommendations, the first is probably the most important to enhance the practical value of simulation models of crop-weed competition. But a balance will have to be found between the applied goals of simplicity and successful prediction, and the research goal of an increased understanding of the processes involved in competition.

\section{REFERENCES}

Ball, D.A., and M.J. Shaffer. 1993. Simulating resource competition in multispecies agricultural plant communities. Weed Res. 33 : 299-310.
Barnes, P.W., W. Beyschlag, R. Ryel, S.D. Flint, and M.M. Caldwell. 1990. Plant competition for light analyzed with a multispecies canopy model. III. Influence of canopy structure in mixtures and monocultures of wheat and wild oat. Oecologia 82 : 560-566.

Bauer, T.A., D.A. Mortensen, G.A. Wicks, T.A. Hayden, and A.R. Martin. 1991. Environmental variability associated with economic thresholds for soybeans. Weed Sci. 39 : 564-569.

Beyschlag, W., P.W. Barnes, R. Ryel, M.M. Caldwell, and S.D. Flint. 1990. Plant competition for light analyzed with a multispecies canopy model. II. Influence of photosynthetic characteristics on mixtures of wheat and wild oat. Oecologia 82 : 374-380.

Cousens, R., P. Brain, J.T. O'Donovan, and P.A. O'Sullivan. 1987. The use of biologically realistic equations to describe the effects of weed density and relative time of emergence on crop yield. Weed Sci. $35: 720-725$.

Dunan, C.M., F.D. Moore III, and P. Westra. 1994. A plant process-economic model for wild oats management decisions in irrigated barley. Agric. Syst. 45 : 355-368.

Graf, B., and J.E. Hill. 1992. Modelling the competition for light and nitrogen between rice and Echinochloa crus-galli. Agric. Syst. $40: 345-359$.

Graf, B., O. Rakotobe, P. Zahner, V. Delucchi, and A.P. Gutierrez. 1990a. A simulation model for the dynamics of rice growth and development : Part I- The carbon balance. Agric. Syst. 32 : 341-365.

Graf, B., A.P. Gutierrez, O. Rakotobe, P. Zahner, and V. Delucchi. 1990b. A simulation model for the dynamics of rice growth and development : Part II- The competition with weeds for nitrogen and light. Agric. Syst. $32:$ 367-392.

Jones, J.W., K.J. Boote, S.S. Jagtap, G. Hoogenboom, and G.G. Wilkerson. 1987. SOYGRO V5.4 : Soybean crop growth simulation model user's guide. Agric. Eng. Dep. and Agron. Dep., Univ. of Florida, Gainesville. Florida Agric. Exp. Stn. J. No. 8304.

Kiniry, J.R., J.R. Williams, P.W. Gassman, and P. Debaeke. 1992. A general, process-oriented model for two competing plant species. Trans. ASAE 35 : 801-810. 
Kropff, M.J. 1993. Mechanisms of competition for nitrogen. Pages 77-82 in : M.J. Kropff and H.H. van Laar (eds.), Modelling crop-weed interactions. CAB International, Wallingford, U.K.

Kropff, M.J., and H.H. van Laar (eds.). 1993. Modelling crop-weed interactions. CAB International in association with the International Rice Research Institute. Wallingford, U.K. 274 pp.

Kropff, M.J., and C.J.T. Spitters. 1991. A simple model of crop loss by weed competition from early observations on relative leaf area of weeds. Weed Res. 31 : 97105.

Kropff, M.J., and C.J.T. Spitters. 1992. An eco-physiological model for interspecific competition, applied to the influence of Chenopodium album L. on sugar beet. I. Model description and parameterization. Weed Res. 32 : 437-450.

Kropff, M.J., S.E. Weaver, and M.A. Smits. 1992a. Use of ecophysiological models for crop-weed interference: Relations amongst weed density, relative time of weed emergence, relative leaf area, and yield loss. Weed Sci. $40: 296-301$.

Kropff, M.J., C.J.T. Spitters, B.J. Schnieders, W. Joenje, and W. de Groot. 1992b. An eco-physiological model for interspecific competition, applied to the influence of Chenopodium album L. on sugar beet. II. Model evaluation. Weed Res. 32 : 451-463.

Kropff, M.J., S.E. Weaver, L.A.P. Lotz, J.L. Lindquist, W. Joenje, B.J. Schnieders, N.C. van Keulen, T.R. Migo, and F.F. Fajardo. 1993. Understanding crop-weed interactions in field situations. Pages 105-136 in: M.J. Kropff and H.H. van Laar (eds.), Modelling crop-weed interactions. $C A B$ International, Wallingford, U.K.

Lotz, L.A.P., M.J. Kropff, and R.M.W. Groeneveld. 1990. Modelling weed competition and yield losses to study the effect of omission of herbicides in winter wheat. Neth. J. Agric. Sci. 38 : 711-718.

Lotz, L.A.P., R.M.W. Groeneveld, and N.A.M.A. de Groot. 1991. Potential for reducing herbicide inputs in sugar beet by selecting early closing cultivars. Pages 1241-1248 in: Proc. Br. Crop Prot. Conf. - Weeds, Brighton, 9A-8.

Ryel, R.J., P.W. Barnes, W. Beyschlag, M.M. Caldwell, and S.D. Flint. 1990. Plant competition for light analysed with a multispecies canopy model. I. Model development and influence of enhanced UV-B condi- tions on photosynthesis in mixed wheat and wild oat canopies. Oecologia 82 : 304331.

Shaffer, M.J., and W.E. Larson (eds.) 1987. NTRM, a soil-crop simulation model for nitrogen, tillage, and crop-residue management. USDA Conservation Research Report No. 34-1. National Technical Information Service, Springfield, Virginia. $103 \mathrm{pp}$.

Spitters, C.J.T. 1989. Weeds : population dynamics, germination and competition. Pages 182-216 in : R. Rabbinge, S.A. Ward, and $H . H$. van Laar (eds.), Simulation and systems management in crop protection. Simulation monographs, Pudoc, Wageningen.

Spitters, C.J.T., and R. Aerts. 1983. Simulation of competition for light and water in crop-weed associations. Aspects Appl. Biol. $4:$ 467-484.

Spitters, C.J.T., H. van Keulen, and D.W.G. van Kraalingen. 1989. A simple and universal crop growth simulator: SUCROS87. Pages 147-181 in: R. Rabbinge, S.A. Ward, and H.H. van Laar (eds.), Simulation and systems management in crop protection. Simulation monographs, Pudoc, Wageningen.

Weaver, S.E., M.J. Kropff, and R.M.W. Groeneveld. 1992. Use of ecophysiological models for crop-weed interference: The critical period of weed interference. Weed Sci. $40: 302-307$.

Weaver, S.E., M.J. Kropff, and R. Cousens. 1994. A simulation model of competition between winter wheat and Avena fatua for light. Ann. Appl. Biol. 124 : 315-331.

Wiles, L.J., and G.G. Wilkerson. 1991. Modeling competition for light between soybean and broadleaf weeds. Agric. Syst. 35 : 37 51.

Wiles, L.J., G.G. Wilkerson, and H.D. Coble. 1991. WEEDING: A Weed Ecology and Economic Decision Making Instructional Game. Weed Technol. $5:$ 887-893.

Wilkerson, G.G., J.W. Jones, H.D. Coble, and J.L. Gunsolus. 1990. SOYWEED : A simulation model of soybean and cocklebur growth and competition. Agron. J. 82 : 1003-1010.

Wilkerson, G.G., S.A. Modena, and H.D. Coble. 1991. HERB : Decision model for postemergence weed control in soybeans. Agron. J. 83: 413-417. 
Williams, J.R., C.A. Jones, J.R. Kiniry, and D.A. Spanel. 1989. The EPIC crop growth model. Trans. ASAE 32 : 497-511.

de Wit, C.T., J. Goudriaan, H.H. van Laar, F.W.T. Penning de Vries, R. Rabbinge, $H$. van Keulen, L. Sibma, and C. de Jonge. 1978. Simulation of assimilation, respiration, and transpiration of crops. Simulation monographs, Pudoc, Wageningen, 141 pp. 